\title{
EESTI LUULE TAEVALAOTUS. TÄHEKUJUNDI FUNKTSIOONID JA SEMANTILINE TÜPOLOOGIA XIX SAJANDI TEISEL POOLEL JA XX SAJANDI ALGUSES
}

Õnne Kepp

TEESID: Eesti kultuuri esmatunnetusobjektiks võib lugeda loodust ja sellega on seotud ka eesti rahvusliku identiteedi kujunemine. Käesoleva kirjutise eesmärk on tõsta esile luules kasutatud loodusatribuutide need tähendusvariandid, mis on otseselt seotud nende abil loodava kujundilise identiteedi-pildiga. Ärkamisaja ja sellele järgnenud perioodi poeetiline ilmaruum toetub Eestimaale, eriti taevalaotusele, maised atribuudid on vähemuses. Ärkamisaegne lüürika oli oma loodusatribuutide kasutamisel suunatud taevalaotuse poole, kust leidis vastandlikke nähtusi, mida maine Eestimaa ei pakkunud. Olukord muutus mõnevõrra 1880. aastatest alates, aga ka siis säilitasid taevased nähtused oma kindlad metafoorsed seosed.

Tähe-metafooril on käesolevas artiklis keskne koht, sest see on analüüsitava ajastu luules kõige mitmekülgsem ja eripalgelisem kujund, millel võib leida kolm põhifunktsiooni. 1. Täht kui vaim. Selle seose kontaktid valgusega on tihedad ning esmatähenduses on tegemist Jumala või muude kristlike väljunditega. Inimest hinnatakse tema mõistuse ja vaimusuuruse põhjal, rahvusliku liikumise aegseid suurmehi tõstetakse Jumala staatusse, s.t neid samastatakse tähe kui jumalusega. Mõlemad omavad loovat jõudu. 2. Täht kui hing, inimtunnete väljendamine tähe-kujundi kaudu. 3. Täht kui elavus, kiir, mis puudutab inimese sisemust ja loob vaimu ning emotsioone. Kõige tähelepanuväärsem eesti tolle aja luules on aga isamaa ja rahva tõstmine tähe staatusesse ja tõdemus, et neilgi on vaim ja hing.

MÄRKSÕNAD: identiteet, looduskeskkond, metafoor, semantika, terra-astraalne ruumitunnetus, genius loci 
Indiviidi identiteet on alati seotud ümbritseva keskkonnaga. Eneseteadvustamisel ja enesemääratlemisel mängib kaasa vahekord teiste inimestega, kahekõne meeltega tajutud ja sisemiselt läbi analüüsitud välispidiste nähtustega. Mõjuvõimas kogemus sellest, mis on, oli ja mis tulevikuski võib tulla, kujundab inimese mina-pilti. Kujutlus iseendast ei ole kunagi ühekordne, staatiline ega viljatu. Tänapäeva teoreetikud rõhutavad üha enam identiteedi suunatust tulevikku, s.t enesetunnetuse pidevat arengut, liikumist täiuslikuma ja täpsema identiteeditunnetuse poole, oma olemuse avardumise poole. Identiteediuurimisklassik Stuart Hall on kinnitanud: „Identiteet puudutab küsimust, kuidas me kasutame ajalugu, keelt ja kultuuri pigem kellekski saamise protsessis, mitte niivõrd olemisena: mitte niivõrd küsimus „kes me oleme“ või „kust me tuleme“, vaid „kelleks me võime saada“, „kuidas meid on esitatud (represented) ja kuidas see sünnitab omakorda seda, kuidas me ise ennast esitame“"“ (Hall 1996: 4).

Niisiis - olemuse vältimatu osa, identiteet, kujuneb otseselt välja keskkonnas, milles see figureerib. Vanadel rahvastel on enesetunnetus olnud tihedas koosluses talupojaühiskonnaga, teinud läbi mitmeid teisenemisi, ja kui välispidine elu on muutunud, on reageerinud ka enesemääratlus. Põhimõtteline etapp eestlaste kulgemise loos oli rahvuslik liikumine ja sellele järgnevad aastad, mil üha rohkem inimesi hakkas ennast tundma rahvuse osana. See, kuidas indiviid, luuletaja, nägi ja kujutas ennast ja oma rahvast oma loomingus eelkõige looduse kui peamise väljendusvahendi kaudu, on selle kirjutise tugipunkte.

Indiviidi eneseteadvustamine ruumitunnetuse kaudu on eesti luulele omane läbi aegade. On üldteada, millist osa mängis ja mängib praegugi loodusruum meie kirjanduses. XIX sajandi teisel poolel ja XX alguses oli meie side maastiku ja taevalaotusega väga tugev, maarahvapärane. Linnainimese identiteet hakkas intensiivselt kujunema alles 1920. aastatel. Niisiis võib loodust lugeda eesti kultuuri esmatunnetusobjektiks ja sellega on seotud ka eesti rahvusliku identiteedi kujunemine. Kõigepealt oli tähtis koht, kuhu sa sündisid ja mida tajusid, mis sind ümbritses. Luuletajad tajuvad Eestimaad ennekõike kodukülana, isamaad talumaastiku ja sellega seotud detailidena. Nad on oma identiteeti otsides rännakul, nagu kirjeldab seda Zygmunt Bauman oma artiklis (1996). Loodus ja kultuurmaastikud ilmestavad eesti selle aja luulet rikkalikult. Samal ajal pöördub pilk üles, taevaruumi, ka see on vastuvõtja ja tunnetaja ümber, ja kokku saab üks kindel ilmaruum.

Kujundi tõlgendus on alati subjektiivne ja sõltub analüüsija teadmistest ja kogemustest, valmisolekust avada see „miski“, mis on teksti esmatasandilise lugemise ülene. Juri Lotman on kirjutanud tähenduse probleemist kunstilises tekstis ja näidanud, et kultuuri, kunsti, kirjanduse kui 
märgisüsteemide uurimine sisust, s.t tähenduse probleemist eraldi kaotab igasuguse mõtte (Lotman 2006: 65). Lotman rõhutab, et igasugune kunstiline tekst suudab täita oma sotsiaalset funktsiooni vaid esteetilise kommunikatsiooni olemasolu korral tema kaasaja kollektiivis (samas: 475). Seega peab ka tänapäeva kirjandusteadlane mõistma ajaloo kulgu ja kultuurilisi nüansse, süvenema (luule)teksti kujundipilti, analüüsima erinevaid tähendusvõimalusi ja semantiliste struktuuride eri tasandeid. Käesoleva kirjutise eesmärk on tõsta esile luules kasutatud loodusatribuutide need tähendusvariandid, mis on otseselt seotud nende abil loodava kujundilise identiteedi-pildiga. Keskkonnadetail, selle metaforiseerimine, semantiline väljund ja funktsioonid, eneseteadvustamise meetodid - kõige selle kaudu kujunes eesti luule(taja) mina-kuvand, mis kulgeb eri arengusuundades läbi aja ja ruumi.

Ärkamisaja ja sellele järgnenud perioodi poeetiline ilmaruum toetub eelkõige Eestimaale ja taevalaotusele. Kristlikust mõttelaadist pärit Jumala-kiitus väljendub puhtromantilises vastanduses valgus-pimedus, kusjuures viimast poolust kohtab tunduvalt vähem. Valgus on väga kindel Jumala-väljendus, ka päike-kuu kannavad seda funktsiooni. Pilve-kujundit kasutatakse nende vastandpaaride väljatoomisel abivahendina. Maised atribuudid on vähemuses: mõningal määral puu ja lill. Metsa-kujundit hakkab kindlapiirilise semantikaga kasutama alles Juhan Liiv sajandivahetusel, andes Mihkel Veske saksapärasele maastikupildile indiviidikeskse üldistuse. Ka meri esineb luuletajatel tagasihoidlikult, enne kui Anna Haava selle oma poeetilise süsteemi osaks võtab, jällegi sajandivahetusel. Üldistavalt võib öelda, et ärkamisaegne lüürika oli oma loodusatribuutide kasutamisel suunatud taevalaotuse poole, kust leidis vastandlikke nähtusi, mida maine Eestimaa ei pakkunud. Olukord muutus mõnevõrra 1880. aastatest alates, aga ka siis säilitasid taevased nähtused oma kindlad metafoorsed seosed.

Tähe-metafooril on käesolevas artiklis keskne koht, sest see on analüüsitava ajastu luules kõige mitmekülgsem ja eripalgelisem kujund. Muidugi on täht ekvivalent valgusele (tähevalgus) ja kannab selget kristlikust traditsioonist tulenevat semantikat. Samuti on ta paljudes luuletustes romantiline ideaalabstraktsioon, mille tähendust on raske, kui mitte võimatu määratleda. Aga tähel on mitmeid lisavarjundeid, mille tõttu ta kuulub rikkalikema semantikaga loodusatribuutide perre, kui me räägime XIX sajandi luulest.

Tähe-metafoori kujunemisel on tähtsad 1870. aastad, mil selle võtavad oma luules kasutusele Lydia Koidula ja Ado Reinvald. Koidula pikem luuletus „Kukkus tähte taevast“, mis on kirjutatud 1870, loob pildi tähest kui jumalikust jõust inimese elus - igas inimeses on peidus jumalik alge. Tä- 
helepanuväärne on luuletaja tõdemus, et ka eesti rahval on põues jumalik täht, kes teda hoiab ja kaitseb.

„Kukkus tähte taevast“ - Ei sa näinud,

Kuhu laotuses langes ta?

Taeva teed on läige läbi läinud,

Mullalise südant otsima.

I n i m e s e põ u e kitsas piires

Taeva tütre terad asuvad:

Need, kes viibind Looja võlvi viires,

Loodud looma rindus kosuvad!

[---]

Eesti rahvas! taevast langes tähte

Sinu pimeduse põue ka!

Eesti rahvas! inglikätt ka nähte

Teda eesti põues valvama!

Mõni pööris koju - kus veel vahvas

Vaim sull' valvab küünalt kedage:

Järele seal rända, eesti rahvas!

Edase seal, rahvas, edase! (Koidula 1969: 316-317)

Ado Reinvald kasutab tähe-kujundit läbivalt oma 1870. aastate luulekogudes („Viljandi Laulik“ 1871, selle II osa 1875 ja III osa 1877 ning „Õitsi Ööpik“ 1876), luues mitmekülgse semantilise võrgustiku, kus täht kannab erisuguseid tähendusi.

1. Täht on Jumal, kes kaitseb ja valvab inimest ning ka isamaad, ta võib tõusta ja loojuda, kõrval seista ja kaduda. Aga ta on alati olemas ja tema poole saab hädas pöörduda. Ta on hea käekäigu alus.

2. Eelnevaga seondub, et täht on õnn (õnnetäht). Seda seost kasutab autor tihti.

3. Täht väljendab inimvaimu, millel on seos jällegi Jumala kui loova vaimuga. Tähega võrdsustatakse Eesti Põllumeeste Selts kui vaimu/vaimsuse kandja ja mitu ärkamisaegset algatust, ka eesti uus elu uutes tingimustes (prii rahvas ja elutäht). Kuid riigitruuduski pole siin teisejärguline - Vene keiser on samuti täht. See tähendab juba poliitilist seisukohavõttu.

4. Mitmed emotsioonid on seotud tähe-kujundiga: armastus, igatsus, lootus.

Reinvald on esimene, kes luuletab konkreetsest tähekogust ja nimetab tähte nimepidi - ta räägib Linnuteest ja Põhjanaelast, mis aitavad leida elus õiget sihti ja käia etteantud rada. Luuletus „Põhjanael“ on pühendatud Soomele ja seal ütleb luuletaja: 
Ma vaatan kaugelt koduilmast,

Kuis kõrgel liigub tähte pael.

Ei aga kustu minu silmast

Sealt Soome taevast põhjanael.

[---]

Oh põhjanael ja põhja rahvas,

Nüid olge märgiks minule:

Et oleks ma nii truu ja vahvas

Ja seisaks nõnda kindlaste! (Reinvald 1904: 72-73)

Järgmise kümnendi teisel poolel ja sajandi lõpukümnendil jätkavad ja kinnistavad Anna Haava, Karl Eduard Sööt, Jakob Liiv ja Jakob Tamm tähekujundi kasutamist eelnimetatud tähendustes, eriti just emotsioonide väljendajana, aga ikka seoses valgusega, jumalasäraga.

Sajandivahetuse poeesias on erilisel kohal eksistentsiaalprobleemid, tähelepanu vääriv on nende esinemissagedus ja kandejõud. See tendents paistab silma nii metafooride valikul kui ka üldises kujundijaotuses, säilitades tähenduslikkuse hiljemgi. Niisuguses kontekstis mõjuvad uudselt Anna Haava loomingulised püüdlused ületada luules laialt levima hakanud subjektiivse elu hallust ja kitsarinnalisust ning tõsta esile isiklikku ja intiimset.

Anna Haava luule eksistentsiaalne alus on siiralt religioosne, väljendades elu väärtustatud jumaliku aktina, mitte niivõrd protsessuaalse liikumisena. Kujundilised vahendid on üle võetud Vanast Testamendist ning on seega ususümbolid (valgus, pimedus, täht jt). Toetudes piiblisümboolikale, on Haava loonud laia haardega kujundisüsteemi, et näidata inimese ja Jumala loomulikku seost minateadvuses ning ümbritseva vastuvõtus. Tema kujundisüsteemis on kesksel kohal valgus, mis kehastab jumalikku absoluuti ja mille kaudu vaadatakse tervele maapealsele elule. Valgus kui Jumala metafoor on XIX ja XX sajandi vahetuse eesti lüürikas sagedane kujund, ilma temata on pimedus, mõttetu maapagu, kus igasugune eluvõitlus on lootusetu:

Valgusele on mind Jumal loonud -

Pimedus ei tohi võtta mind!

Õnnistust kõik võitlused on toonud -

Issand, selle eest ma tänan sind. (Haava 1924: 66)

Või teine näide seonduvalt tähega:

Valgus on õues,

Valgus mu põues,

Kõlamas kõrvus kui kannelde hääl;

Lootuselaevuke lendamas jälle, 
Hiilgamas õnnetäht mägedel sääl -

Kaugel. (Haava 1924: 16)

Villem Ridala tõlgendab neid kujundeid järgmiselt: „Niimoodi arenenud usulise ümbermoonduse kaudu seletubgi see maine armastus. Kõik saab selle tõttu üliloomuliku helgi. Ja tundub, kui oleksgi hingel tiivad, mis üles kannavad maisest kaduvikust" (Ridala 1914/1915: 28).

Kui valgus on igavese jumaliku alge metamorfoos kõiksusse, siis teised süsteemi sõlmpunktides asuvad metafoorid päike ja tuli on Jumala kehastus maises eksistentsis, selle võimalikuks tegemine kõrgema väe abil. Esimene neist on kõige elava eeldus, nn jumalik eluväljendus, teine jumaliku absoluudi sisu ja igikestvuse alus. Päike rõhutab elu võimalikkust üldse, jumaliku harmooniaga kaasnevat positiivset programmi. Jumalaarmu, headust ja halastust kandev metafoor täht on poeetilises mõtlemises samuti strateegiliselt vajalikul kohal, selles avaneb kõrgem vaim kui kaitsja, kui inimlapse saatuseideaal. Siin kehtib religioosne moto: käi minu järel ja sa saad õndsaks. Koidulalikku Jumala ja inimese kahekõnet, kõrgema väe puudutust läbi vaimu ja emotsioonide näitab Anna Haava paljudes luuletustes:

Vaatsin taevasina sisse,

Tähte poole ülesse,

Ja säält lendas kiir nii hele

Kurvastatud südame.

Kuu, see vaatas õnneliselt

Minu kambri korraga;

Mina aga kõnelesin

Oma Taevaisaga. (Haava 1924: 159)

Tihti esineb Haaval täht koos valgusega, võimendades veelgi religioosset hardust ja õnneihalust (luuletused „Ära küsi“, „Vaiksemaks ja sügavamaks“, „Valgus mu õues“ jpt). Tuleb lisada, et religioosne elutunnetus ei olnud sajandivahetusel ainult romantiline hingepaisutus või paleuslik ideaalikultus, vaid eelkõige ühiskondlikult teadvustatud ja aktsepteeritud norm, mis pani luuletajad valima (piiblist) just niisuguseid apellatiive ja metafoore. Kõrgendatud usuliste veendumuste ja nendele vastava loomingulise ainekasutuse tõttu võib ka Haava kohta kinnitada, et ta ,jagab kõik nähtava ja mõeldava kolmeks. Need on: maailm, inimene ja Jumal. Tema, inimene, seisab looduse ees, tema taga on Jumal, mitte looduse keskel“ (Visnapuu 1921: 33). Niisiis on Anna Haava elutunnetus pigem loogiline ja mõtteline kui meeleline. 
Inimvaimu kõrgusest ja lennukusest, eriti luule ja loomingu ülimuslikkusest kirjutavad aga teised lüürikud (Jakob Liiv: „Sa tähe läikeks mõttetaeva pääl...", Jakob Tamm: „täht toob vaimu teravust“"). Ka see on jumalik puudutus, eesmärgiga äratada ja ülendada inimest. Vaim(sus) kannab sidet eluga, on elusihi ja eluoskuse väljendaja („elukoidu tähed“, mida kordab Jakob Liiv). Seega on taevane ja maine tihedalt seotud, aga mitte nii väga vastandatud, nagu puhtromantilisest luuleseadest võiks eeldada. Siinse ilma elu on samavõrd tähtis. Aga suund on ikka Jumala poole, sest sealt saab kõik maine alguse ning teekond siinses ilmas on hingelunastuse eelmäng. Täht/vaim on nendel autoritel kestvuse sümbol, mis ühendab kaht ilmaruumi.

Traditsiooni täiendaja Juhan Liiv kasutab tähe-metafoori juba uues kontekstis ja tähenduses. Korrates järjekindlalt ka varasemaid tähendusseoseid, pöördub ta rohkem maise elu juurde, märgistades inimese käekäiku ja eluteed just tähe-kujundi kaudu. Rõhutades inimeksistentsi ja selle keerukust, peab luuletaja vajalikuks seda väärtustada kõrgemate jõudude abil:

Hei! Elu sõda ja tuli on, õhk Taara tammikust.

Hei! Elu julgus ja tugevus on, täht tähevanikust. (Liiv 1989: 120)

Või veidi pessimistlikum ja emotsionaalsem tundepurse:

Oh sõbrad, kel õnneks läks kummarda'

oma hinge kõrguse tunnil:

kes leidis kõrgema jumala -

ja põlvitas südame sunnil -

see põlvitas pühal minutil

ise e $\mathrm{n}$ e $\mathrm{s}$ e hinge ette!

[---]

Kes sellel pühal minutil

läks elutähest mööda, see kustus, kadus jäljetult, kui täht, mis valgustas ööda. (Liiv 1989: 67)

Juhan Liivil puuduvad abstraktsed paisutused, tema tahab näha elu ja seejuures on ka väljendusvahendid konkreetsemad. Liivi luule semantilise keskpunkti loodusatribuutide seas kujundab mets ja mõni muugi maine/ mullane kujund. Tähte vajab ta kõige üleva ja väärtuslikuma näitamiseks nendeks on elu ja isamaa. Kui Koidula väärtustas taevaseid jõude isamaa ja rahva teenistuses juba ärkamisaja alguses, siis otsene Eestimaa tõstmi- 
ne kõrgemale semantilisele tasandile toimub Liivi luules. Ja ta teeb seda järjekindlat läbi kahe aastakümne, ka 1905. aasta revolutsiooni ja uue elu paisutuses. Luuletuses „Emale“, mis kirjutatud 1908, ütleb luuletaja:

Kõrget, suurt ma leidsin üles -

sind ei leidnud, kodumaa.

Palju tähti taeva süles -

sind ei siiski näinud ma. (Liiv 1989: 56)

Või tõsisem etteheide olukorrale ja poliitiline seisukohavõtt:

Soome sugud peaks surema Venemaa tugevus' pärast?

Üks täht siis vähemaks jääks ju su taevas, rahvaste taevas - kas sa ei tunneks sest kahju?

Üks ja teine kaoks - üksi siis jääksid maailma?! (Liiv 1989:

184)

Niisiis lisab Juhan Liiv eelnevale avarale tähendusväljale veel ühe, rahvuspoliitilise tähenduse: täht kui isamaa ja rahvas, mis eesti luule arenguloos oli ainukordne. Liivist alates kordavad eesti luuletajad kriitilistes ühiskondlikes situatsioonides just sedasama rahvuspoliitilist seost, alates juba 1913. aastast Anna Haava luuletusega „,Euroopa“kui vaataks“.

Käesolev sisuline analüüs põhineb ajavahemikul 1870-1913, mida võib tähe-kujundi semantilises arengus pidada esimeseks põhjaloovaks perioodiks. Peamised kirjutajad on pärit ärkamisaegsest õhkkonnast, nende impulsid pärinevad rahvusliku liikumise poeetilistest põhimõtetest. Traditsioon kulgeb edasi XX sajandisse ning Ado Reinvaldi kujundisüsteem kestab vääramatuna mitmetes kordustes ja varieerumistes. Ainult Juhan Liiv, erakordne, nagu ta oli, põimib juba läbikirjutatud tähendusseostele juurde oma hingevaludes läbi tunnetatud tegelikkuse. Uuest, nooreestlaste põlvkonnast ei pööranud põhiluuletajad tähele mingit tähelepanu, kuigi kirjutati palju valgusest kui vabadusest, parema tuleviku ja uue elu ootusest.

Usulis-eksistentsiaalne arengujoon eesti luules murdub XX sajandi esimese kümnendi teisel poolel mitmeks erisuguseks maailma tajumise ja tõlgendamise viisiks. Enam levinud suhtumisi koondab ja laiendab Marie Heibergi looming. Eespool analüüsitud absoluudi- ja igavikuigatsus on temagi puhul määrav elutunnetuslik alus. Heiberg võtab üle Haava poolt väljaarendatud kujundisüsteemi märksõnad (valgus, pimedus, päike, täht) ja ideaalid. Poeetilises kontekstis aga muutub metafooride tähendusväli ja ideeline suunitlus. Heibergi lauludes taandub üha enam piibel ja usuline sümboolika ning tema luule liigub eksistentsi loomulikuma tunnetamise poole. Nii kohtame temal Suurt Loojat tunduvalt harvem (peamiselt hilisemal perioodil seoses haiguse süvenemisega) ja seega puudub otsekon- 
taktne jumalaihalus. Haava noore õpilasena otsib temagi varjupaika üksinduses, kuid elu jälgimisel ja ülendamisel ei tõuse ta silmad ainult taeva poole, vaid pöörduvad vaiksesse endassesüvenemisse ja loodusvaatlusse. Peagi avardub Jumala mõiste elukõiksuse ja lõpmatuse mõisteks ning see lubab tingimisi Marie Heibergi tunnetuslaadi pidada panteistlikukski. Veelgi enam: sageli näeb ta oma unistustes ja lootustes inimlikku maapealset õnne ning rahulolu. Metafoor valgus väljendabki Heibergi luule poeetilises kontekstis vaba inimese hingestatud elutahet, mitte ainult jumalaarmastust ja paratamatut võitlust kunagise tasu nimel. Valgus on ime, mitte konventsioon.

Murranguliste aastate luulestruktuuride seotus ja pidevus avaneb mitme kirjutaja kalduvuses sümbolismi ning unefantaasiasse. Marie Heibergi puhul varieeruvad tuttavad metafoorid valgus ja täht nüüd haavalikult abstraktselt ideaalilt ennolike sümbolitaguste igavikuotsingute suunas. Üksikutes Heibergi luuletustes kohtab ihaldatava igaviku otsingul omapärast ühtsustunnet jumaliku kõiksusega, vaatamata autori kiusatusele kujundit kumuleerida ja abstraksioneerida.

Küll vaatan vaiksel tähte valgel

ma üle metsa, üle maa,

kus valge tee kaob kaugusesse -

kuid minu hing ei rahu saa.

[---]

Mu süda otsib igavikku, mu hinges nutab igatsus... (Heiberg 1988: 17)

Rangelt kristlik taevalikku ainuvõimu kandev sümbolisüsteem hakkab pikkamisi avarduma panteistlikuks maailmamõistmiseks, mille luulendamisel asendab endist abstraktset metafoori plastilisem kujundikeel. Heibergile lisaks luuletavad uuenevas keeles ja teisenevas poeetilises mõtlemises ka Gustav Suits ja Jaan Kärner, jõudmata siiski kujunditüpoloogilise haardeni. Mainida võiks Kärneri 1913. aastal ilmunud esikkogu „Tähtede varjud“, mis aga tähe tähendust sisuliselt ei ava ega kasuta. Naljaga pooleks võiks öelda, et pealkiri viitab hoopis autori suurtele eeskujudele - Juhan Liivile ja Ernst Ennole, kellest on kirjutaja inspiratsiooni saanud. Nemad on need „tähed“ ja tema luuletused vaid „varjud“.

Kujundisüsteemide vahetumine XX sajandi haku kirjanduskultuuris ei olnud järsk ega ootamatu. Põhimõtteline pööre valmis pikkamisi ja märkamata, kus ärakulutatud järelromantilises idüllis arenes muutuva ühiskonna uus maailmanägemine ja selle kujundiline mõtestamine. Ruumitajumise ja enesetunnetuse aluseks ei olnud enam loodusatribuutidega väl- 
jendatud religioosne tugi, vaid eksistentsiaalne kooslus. Aga religioosne diskursus saadab veel pikka aega eesti luule maailmapilti.

Tähe-kujundi prevaleerimine XIX sajandi teise poole ja XX sajandi alguse eesti lüürikas on seletatav vaimuliku kirjanduse valitsemisega kultuuripildis ja inimese elus üldse. Mitte ainult piibel ei olnud religioosse tunnetuse aluseks, vaid ka igapäevane lauluraamat ja muu kristlik kirjavara. Kontakt rahvausundiga, kus taevastel nähtustel on kandev roll (M. J. Eisen, U. Masing, O. Loorits), otseselt puudus. Ei aidanud ka populaarne rahvuseepos ega võimas rahvaluulepärand. Siiski võime leida vana maailmasüsteemi ja arhailise mõtlemisviisi pidepunkte läbi kristliku elutunnetuse ka eesti luules. Iidses tähetarkuses olid tähed inimeste hinged (Kasak 2003: 112; Kuperjanov 2003: 159) - ja nii valdavalt meie poeesiaski. Piibli kui universaalse ajastuteksti kaudu on meieni jõudnud ka mitmed arhetüüpsed metafoorid.

Kokku võttes ja järeldusi tehes võib arutleda järgmiselt.

Täht on maailma rahvaste mütoloogias ja sümboolikas polüsemantiline metafoor (Cirlot 1983: 309-310), nii ka eesti lüürikas. Sageli esineva romantilise ideaalabstraktsiooni kõrval on tal aga XIX ja XX aastasaja vahetuse eesti luules kolm põhitähendust, mis on omavahel tihedalt läbi põimunud.

I. Täht kui vaim. Selle seose kontaktid valgusega on tihedad (tähevalgus paljudel luuletajatel) ning esmatähenduses on tegemist Jumala või muude kristlike väljunditega (nt inglid). Meie luulele on aga iseloomulik maisuse ja inimese rolli tähtsus semantilises väljas, s.t et romantismiaegse luule romantilised vastuolud ja kontrastid ei ole nii eristatavad ja konkreetsed, kui võiks eeldada. Pigem on tegemist ühtse kooslusega, mis teineteisest sõltuvad ja üksteist täiendavad. Suhe on kongeniaalne. Inimest hinnatakse tema mõistuse ja vaimusuuruse põhjal, rahvusliku liikumise aegseid suurmehi tõstetakse Jumala staatusse, s.t neid samastatakse tähe kui jumalusega. Mõlemad omavad loovat jõudu.

II. Täht kui hing. Teiseks kõige levinumaks seoseks on inimtunnete väljendamine tähe-kujundi kaudu. Emotsionaalne paisutus saadab armastust, igatsust, lootust, õnneihalust jne. Tähe kaudu avaneb hingepilt. Lootus heale käekäigule, õnnetähe otsimine ja selle kaudu oma elu mõtestamine saadab aastakümneid eesti luulet ning on täheldatav samas semantilises seoses tänapäevalgi.

III. Täht kui elavus. Täht on elusolend ja tal on võime teha elavaks. Ta on see kiir, mis inimese sisemust puudutab ja loob vaimu ning emotsioone. Täht on üldiselt maskuliinne, nagu meie folklooriski, kus pöördutakse tähe kui poisikese või mehe poole (Peegel 2004: 298). Kõige tähelepanuväärsem eesti tolle aja luules on aga isamaa ja rahva tõstmine tähe staatu- 
sesse ja tõdemus, et neil on vaim ja hing nagu inimeselgi (ja Jumalal?). Isamaa-ideaal väärtustub võitluslikel või lootusetutel aegadel (vrd hilisema Henrik Visnapuu, Viivi Luige luulega) kõige ülevama ja kättesaamatuga, mida inimkond on ajast aega samastanud oma iidolitega. Vanad kreeklased ja roomlased andsid taevakehadele nimesid jumalate järgi, meie, eestlased, näeme (aja)pimeduses pea kohal helendavates punktides isamaad. 1940. aastatel kordavad Marie Under ja Henrik Visnapuu isamaa ja rahva ühtsust oma jõulutähes. „Täht süttib taevas üleval, näe, süttib ikka veel!“ ütleb Viivi Luik 1982. aastal kahekõnes Juhan Liiviga.

Tähe-metafooril on analüüsitud perioodil kolm põhifunktsiooni: nähtava religioossuse ja patriootilisuse kõrval võib kinnitada, et täht on kõige enam esteetilisust kandev loodusmetafoor, väljendades ilu ja loovust nii hingeliikumistes kui vaimupüüdlustes.

Oh võiksin taeva telgilt

Kõik tähed paluda

Ja eha hellalt helgilt

Ta ilu laenata!

Oh võiksin kõik, mis ilus,

Mis valgus, ühenda' -

Sind, sind siin elu vilus

Siis krooniks sellega! (Haava 1924: 34)

Minnes lõpetuseks tagasi artikli algusesse ja rääkides ruumitunnetusest ning selle kaudu väljenduvast eesti lüürika identiteedist ajastu peamiste luuletajate loomingus, võib tähele panna tõsiasja, et Eestimaa kui keskne luuletamise objekt ärkamisajal ja selle ümber on tihedalt seotud taevalaotusega. Mõlema semantilised väljad põimuvad, täiendades ja laiendades teineteist. Valgus ja täht sisustavad isamaatunnetust ja Eestimaa-mõistmist. See annab tugeva aluse kujuneva identiteedi terra-astraalsele kooslusele - maa ja taevas on üks lahutamatu tervik ning inimese mina-pildis esmatähtis. Ruum annab elavale eksistentsi. Seda ühtsust näitab ilmekalt isamaa ja rahva sulandumine taevasse, nagu tähe-kujundi semantikast välja võib lugeda. Täht on koha vaim selle kõige avaramas mõttes.

\section{KIRJANDUS}

Bauman, Zygmunt 1996. From pilgrim to tourist, or a short history of identity. Questions of Cultural Identity. Eds. Stuart Hall, Paul du Gay. London, Thousand Oaks, New Dehli: Sage Publications, pp. 18-36. 
Cirlot, J. E. 1983. A Dictionary of Symbols. Second Edition. New York: Vail-Ballou Press.

Haava, Anna 1924. Luuletuskogu. Tartu: Postimees.

Hall, Stuart 1996. Introduction: Who needs „identity“? - Questions of Cultural Identity. Eds. Stuart Hall, Paul du Gay. London, Thousand Oaks, New Dehli: Sage Publications, pp. 1-17.

Heiberg, Marie 1988. Käisin üksi tähte valgel. Tallinn: Eesti Raamat.

Kasak, Enn 2003. Iidne tähetarkus. Tallinn: Argo.

Koidula, Lydia 1969. Luuletused. Tallinn: Eesti Raamat.

Kuperjanov, Andres 2003. Eesti taevas. Uskumusi ja tõlgendusi. Tartu: Eesti Folkloori Instituut.

Liiv, Juhan 1989. Sinuga ja sinuta. Tallinn: Eesti Raamat.

Lotman, Juri 2006. Kunstilise teksti struktuur. Tõlk. Pärt Lias. Tallinn: Tänapäev.

Peegel, Juhan 2004. Nimisõna poeetilised sünonüümid eesti regivärssides. Tallinn: Eesti Keele Sihtasutus.

Reinvald, Ado 1904. Ado Reinvald'i Laulud. Jurjev/Tartu: T. Kukk.

Ridala, Villem 1914/1915. Anna Haava. Tartu: Postimees.

Visnapuu, Henrik 1921. Vanad ja vastsed poeedid. Tartu: Noor-Eesti Kirjastus.

\section{Summary}

\section{THE VAULT OF SKY OF ESTONIAN POETRY. THE FUNCTIONS AND SEMANTIC TYPOLOGY OF THE IMAGE OF THE STAR IN THE 2ND HALF OF THE 19TH CENTURY AND THE BEGINNING OF THE 20TH CENTURY}

The world of Estonian poetry during the period of national movement and the following years relies on Estonia and the vault of sky. The praise to God that originates in the Christian mentality is expressed in the purely romantical opposition light-darkness, the contrast sun-moon also carries the function. Clouds form the aid to help exist the two pairs. The more down-to-earth attributes are fewer - to some extent tree and flower have been used. Forest with its more realistic background only appears at the time of the change of centuries, supplementing the sea-metaphor and its post-romantic sub-stream.

Star is the polysemantical metaphor in the mythology and symbolics of the peoples of the world, including Estonian lyric poetry. Next to the frequently appearing romantic abstraction of the ideal, in the Estonian poetry of the change of the $19^{\text {th }}$ and the $20^{\text {th }}$ century it possesses three main meanings that have densely intertwined with each other.

1. Star as a spirit. The contacts of this association with light are close (starlight) and its primary meaning concerns the expressions of God or 
other Christian phenomena. Estonian poetry, however, is characterized by the importance of the role of secularity and the human in the semantic field, i.e. the contradictions of the time of romanticism cannot be distinctively differentiated. We are rather dealing with a uniform symbiosis, and the relationship is congenial.

2. Star as the soul, the expression of human feelings via the star-image. The emotional dilation sends love, longing, hope, desire for happiness and other positive feelings. The picture of the soul is revealed by the star.

3. Star as liveliness. The star is a living creature and it has the power to make things alive. The most remarkable in the poetry of the period is the raising of fatherland and nation to the status of the star and the acceptance that, similarly to humans, they have spirit and soul. The kind of fatherland-ideal becomes valued also later during the combative or hopeless times with the most sublime and unavailable that the mankind has always identified with its idols. Ancient Greeks and Romans named the astral bodies after their gods, we, Estonians, see our fatherland in the glowing dots in the darkness (of time) above our heads.

Star-metaphor has three main functions in the period under discussion: next to the visible religious and patriotic aspects it can be assured that the star is the natural metaphor that carries aesthetic appeal more than anything else. It expresses beauty and creativity both in the sense of the streaming of the soul as well as the endeavours of the spirit.

While talking about the sense of space and via this the identity of Estonian lyric poetry in the creation of the main poets of the era, it could be noted that Estonia as the central object of poetry during the period of national awakening and around is strongly connected with the vault of sky. The semantical fields of both intertwine, supplementing and broadening each other. Light and star furnish the sense of fatherland and the understanding of Estonia. This provides with a solid basis for the terra-astral symbiosis of the developing identity - earth and sky form a single inseparable whole that becomes primary in the self-reflection of man. The space gives existence to the living. The unity is expressively demonstrated by the merging of the fatherland and the nation into the sky, as can be read from the semantics of the star-image. Star is the spirit of the place in its widest sense.

KEY WORDS: identity, natural environment, metaphore, semantics, terra-astral spatial perception, genius loci 